\title{
The First Natural Ventilation Assessment in Building Design in Djibouti
}

\author{
Abdou Idris Omar $^{1}$, Abdoulkader Ibrahim Idriss ${ }^{1}$, Omar Assowe Dabar ${ }^{2}$, Abdourazack Ahmed Kayad ${ }^{1}$ and \\ Mohamed Said Darar ${ }^{1}$ \\ 1. Research Center at the University of Djibouti (CRUD/GRE), Faculty of Engineers, Street Djanaleh, B.P. 1904, Djibouti \\ 2. Institute for Earth Sciences, Centre d'Etudes et de Recherche de Djibouti (CERD), Airportstreet, B.P. 486, Djibouti
}

\begin{abstract}
With a sustained period of economic growth, rapidly growing populations and with more diversified economies Africa need sustainable development; hence the greater need for massive investments in energy. Sub-Saharan countries such as Djibouti have the potential and ability to harness their natural ventilation as a passive cooling system for designing new houses. The rapid expansion of the Djibouti city is affecting negatively the environment and the safety and comfort of its inhabitants. Proper atmospheric urban planning and management are key to making cities environmentally friendly and sustainable. Based on energy consumption, climate conditions in Djibouti and numerical analysis using Computational Fluid Dynamics (CFD), it is apparent that the natural ventilation creates a thermally comfortable indoor environment in buildings during the cool season of the year. Measured wind data from two measurement systems are presented and discussed. Statistical analyses, wind rose, Weibull distribution were carried out to understand the natural ventilation characteristic, which is used for evolving the basic criteria for economic viability of building in the semi-arid climate of Djibouti. The study found that it is possible to benefit from natural ventilation in buildings during the cool season of the year.
\end{abstract}

Key words: Computational Fluid Dynamics, airflow simulation, natural ventilation, bioclimatic design, weather data, energy efficiency.

\section{Introduction}

Nowadays, all developing and developed countries are subject to three major constraints that require them to define an energy transition strategy: the higher hydrocarbon price; the needs of their energy security; climate change which negatively affect environment and inhabitant safety and comfort [1-4].

A few researches have been undertaken on bioclimatic design $[5,6]$ in the last twenty years, and many recent research projects have been concerned with natural ventilation [7-9] such as indoor air quality and thermal comfort $[10,11]$ in the context of ventilation. Bruce J.M. [12] presented a generalised neutral height-based theory for natural ventilation through multiple openings in one wall. Axleyand

Corresponding author: Abdou Idris Omar, research fields: energy efficiency in buildings, energy design, thermal comfort, bioclimatic design, applications of computational fluid dynamics.
Emmerich [13] proposed a method for assessing the suitability of natural ventilation in buildings.

For this paper, the main objective is to investigate the integration of the natural ventilation potential under local climate by considering one of the buildings of the University of Djibouti. The building was chosen because the local weather station is fitted on its roof. Accordingly, this work presents the first natural ventilation potential analysis in the Republic of Djibouti, based on satellite estimates and local weather station data through CFD simulations analysis from January to December 2015. Wind-rose diagram and Weibull distribution regarding the building are discussed in subsequent sections. Short analysis of the airflow simulation using CFD was, finally, exposed.

\section{Energy Consumption Context in Djibouti}

Djibouti has no conventional energy resources and depends totally on the outside for energy supplies 
[14-18]. Demands of economic growth and improvements in living standards of Djiboutian people led to higher levels of energy consumption. To speed up economic activities' development with less energy, efforts must focus on three areas: energy saving at all levels of organisation, energy efficiency and the use of renewable energy. Despite this, there is lack of studies focusing on this subject, particularly the topic of the current study which is natural ventilation. Moreover, there is little data that can be used to study natural ventilation excepting some data from DAEM and NASA collected for other purposes. The present investigation will be focused on the potential benefits and feasibility of natural ventilation and to investigate the issues related to its design and simulation methodologies.

In Djibouti, measurements made by the Djiboutian Agency for Energy Management (DAEM [19]), estimates the final energy consumption of the country at approximately 228 ktoe, distributed among the sectors as shown in Fig. 1a. Transportation represents the largest share of consumption (81\%) while the combined residential and tertiary sectors represent $18 \%$. However, when only the electricity is considered, the building sector represents the largest share, about $90 \%$ of the country's consumption as shown in Fig. $1 \mathrm{~b}$.

However, the country experiences electricity shortages and energy problems. The problem of lack of energy is particularly noticeable in habitat areas and public administration which represent more than $70 \%$ of the energy needs of the country.

The break-down of the electricity use in 2013 shows that in most buildings (office and hospital administrations and household) high electricity consumption results from the use of air conditioning as shown in the Fig. 1c. Electrical demand remains dominated by the refresh requirement, namely air conditioning and ventilation, which together account for $75 \%$ of electricity consumption.

This observation should cause a substantial development of the energy research so as to strive towards an optimized conception of buildings.

\section{Topography and Climate analysis}

Bioclimatic design of building requires appropriate climates. It is well known that natural ventilation can work in a moderate climate, such as those in western and northern Europe, California, and others [20, 21]. However, Djibouti located in the horn of Africa has a typical tropical climate and is officially classed as a maritime desert: a climatic region that is hot and humid in winter and extremely hot and humid in summer [22]. In maritime desert the presence of the warm ocean creates a high level of humidity. Temperatures are high at $20{ }^{\circ} \mathrm{C}-30{ }^{\circ} \mathrm{C}$ during the cool season from mid-October to April and $30{ }^{\circ} \mathrm{C}-45^{\circ} \mathrm{C}$ during the hot season from May to September.

Regarding this observation, it is clear that energy efficiency initiatives should focus on air conditioning through bioclimatic or energy efficiency building design. Natural ventilation has the potential to reduce

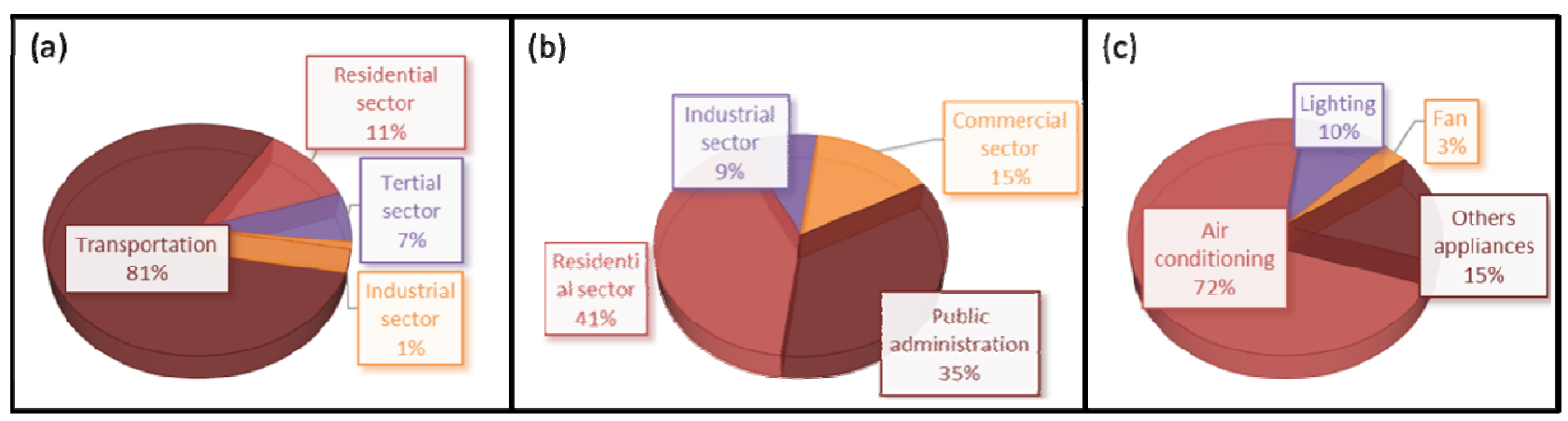

Fig. 1. Data surveys from Djiboutian Agency for Energy Management [19], (a) Sectoral distribution of electricity consumption in Djibouti; (b) Sectoral distribution of final energy consumption in Djibouti; (c) Breakdown of electricity consumption by use-2013. 


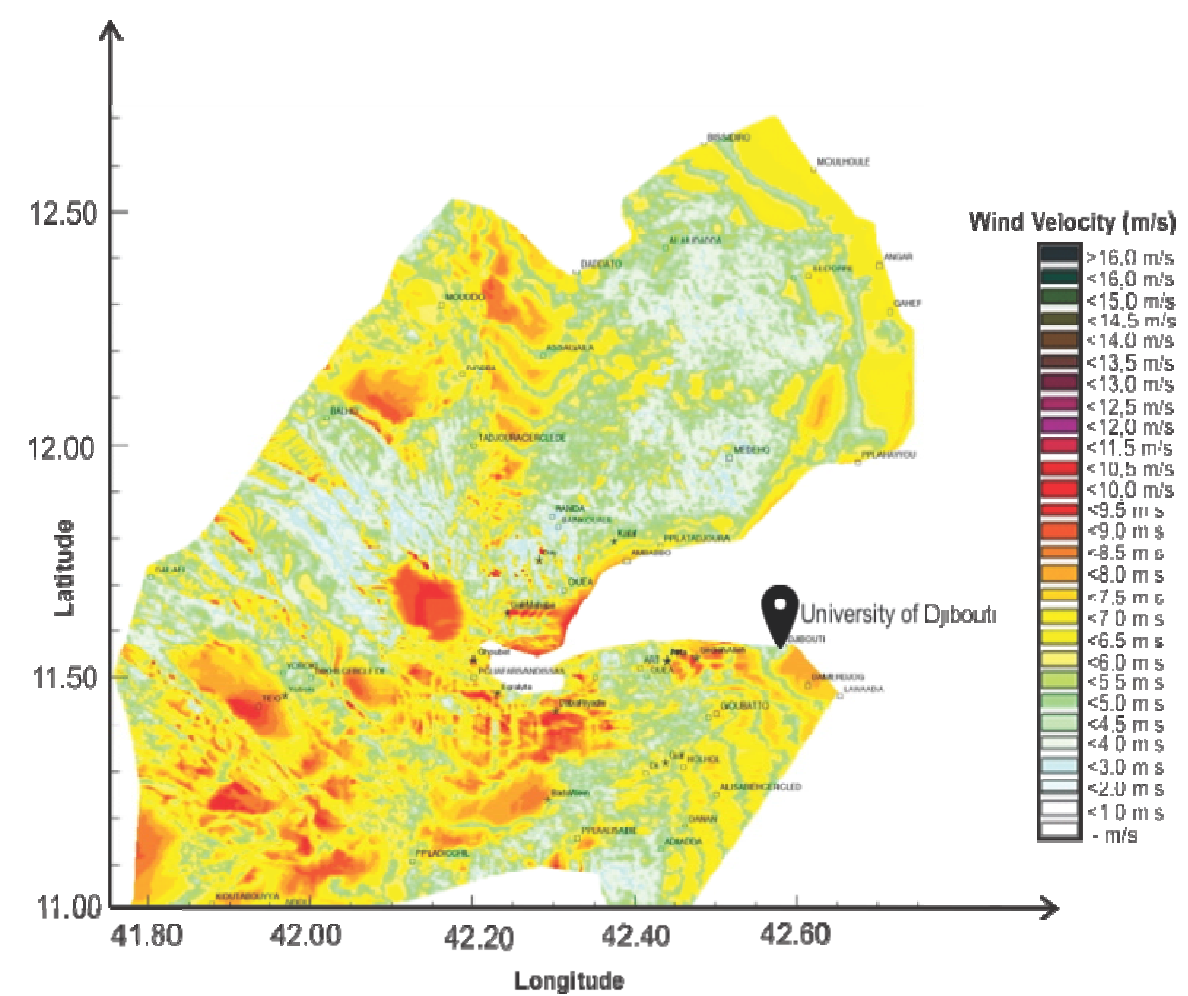

Fig. 2 Geographic distribution of wind velocities in the Republic of Djibouti at $60 \mathrm{~m}$ height [15]. The arrow indicates the position of University of Djibouti.

the energy consumption due to the use of air-conditioning in buildings.

In addition, Djibouti has a considerable wind potential that is not sufficiently exploited. As shown in Fig. 2, Djibouti climate is characterized by high wind intensities with nearly $7 \mathrm{~m} / \mathrm{s}$ in the capital where the study site is located.

This investigation used Djiboutian conditions as a reference to design buildings that use natural ventilation in the University of Djibouti.

The wind speed data were collected over the period of the year from January 2015 to December 2015. Wind speed measurements were made $8 \mathrm{~m}$ above ground level and recorded every five minutes at the station. The geographical location of the station is shown in Fig. 3. The data used in the study can be grouped into two classes, namely observed weather data and satellite observed data of the NASA [23].

The weather station Davis Vantage Pro 2 measures weather data by a set of integrated sensors (anemometer and pyranometer) to the station; the measured data are displayed in a console. The connection between the external sensors and the console is via radio waves on frequency 868.0-868.6 $\mathrm{MHz}$ with a range of $300 \mathrm{~m}$ maximum. The console is equipped with a large backlit LCD screen that views real-time information on the weather conditions (range wind speed: $1 \mathrm{~m} / \mathrm{s}$ to $30 \mathrm{~m} / \mathrm{s}+/-0.01 \mathrm{~m} / \mathrm{s})$. A data logger connected to the console transfers data to a server (PowerEdge R910) via an interface named Weather Link.

To better meet the objectives of the study, the data collected by the local weather station is analysed for a better use of natural ventilation. Fig. 4 (a-b) shows the wind direction frequency and the Weibull distribution of the University of Djibouti. Weibull $\mathrm{k}$ and scale factor c, corresponding to the fit curves, are $5.10 \mathrm{~m} / \mathrm{s}$ and 1.92 , respectively.

The frequency of wind velocity is divided by classes as follows:

- The frequency of calm winds is $68 \%$;

- The frequency of strong winds is $32 \%$; 


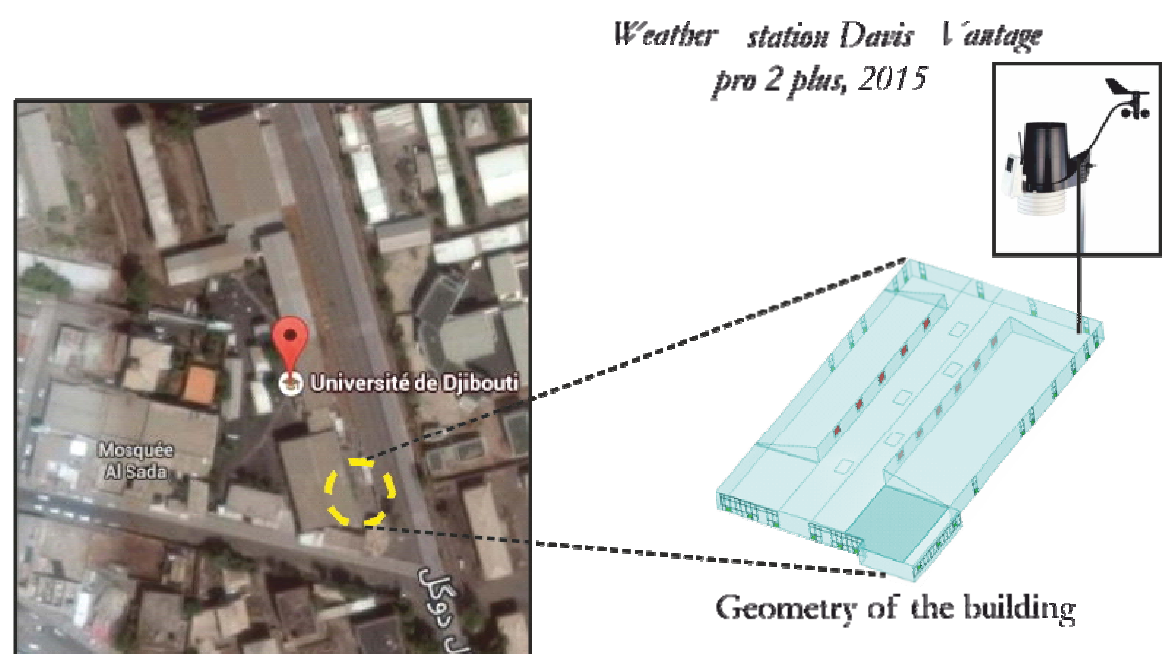

Fig. 3 Map of the case study building University of Djibouti, with measurements setup showing anemometer and wind vane. Data logger with integrated to the console transfer data is powered by solar panels.
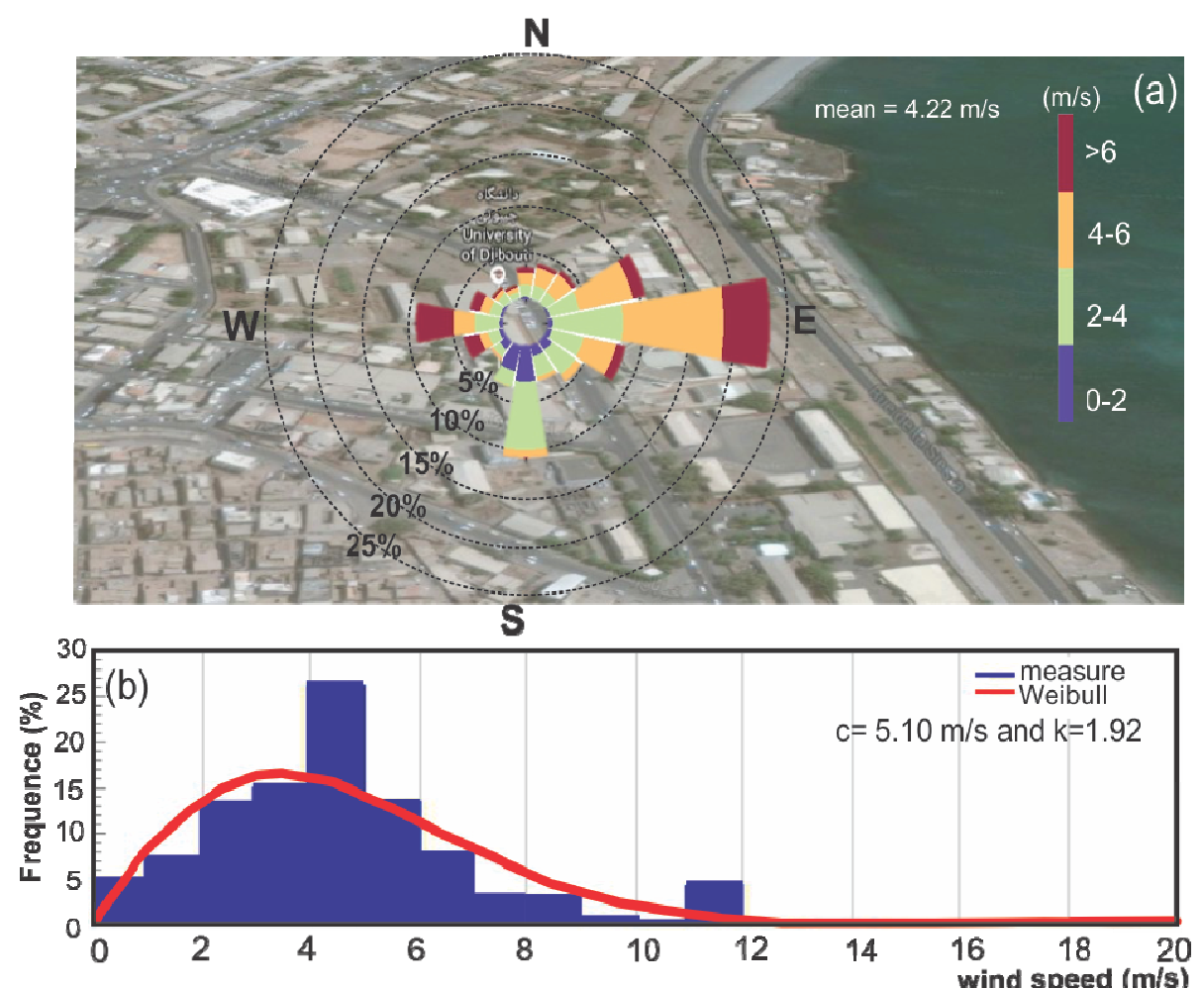

Fig. 4 (a) Wind direction frequency distribution and (b) Weibull parameters values and distribution for wind speeds for University of Djibouti site.

According to the wind rose at the University of Djibouti, the prevailing wind direction is from the East with an average of 90 days per year and occurs primarily in winter. The wind rose also shows some contribution to the southerly flow. This analysis is used to design the building in order to receive maximum winds. In this study, the wind from the east direction is considered for the airflow simulation. Meteorological data regarding the average of temperatures of the site is compared to the satellites data from the NASA as shown in Fig. 5.

The most reliable data is obtained through the collection of ground-measurement data at a specific site over the course of one year or longer. Principally 


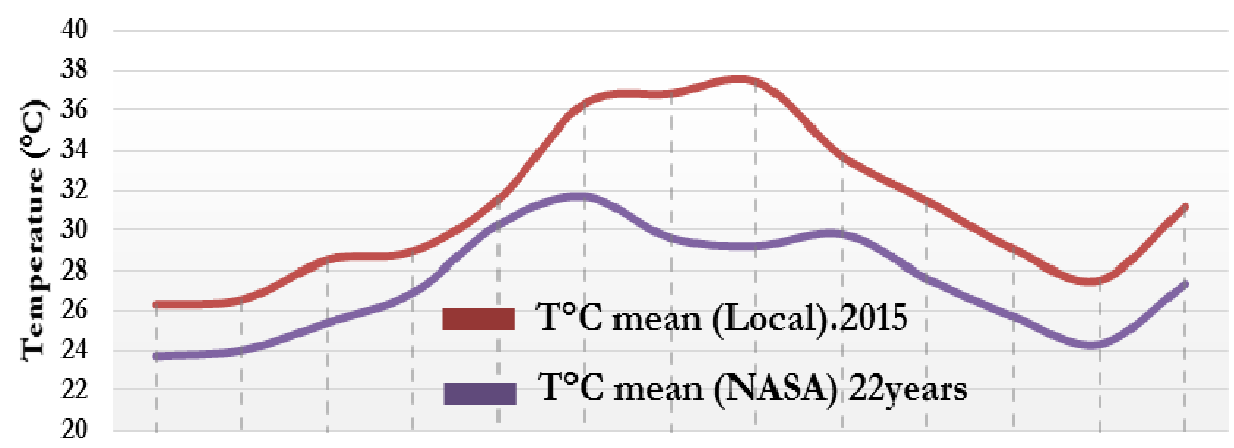

Jan. Feb. Mar. Ap. May. June. Jul. Au. Sept. Oct. Nov. Dec. Year Month

Fig. 5 The comparison of mean temperatures for local weather station and NASA data [22].

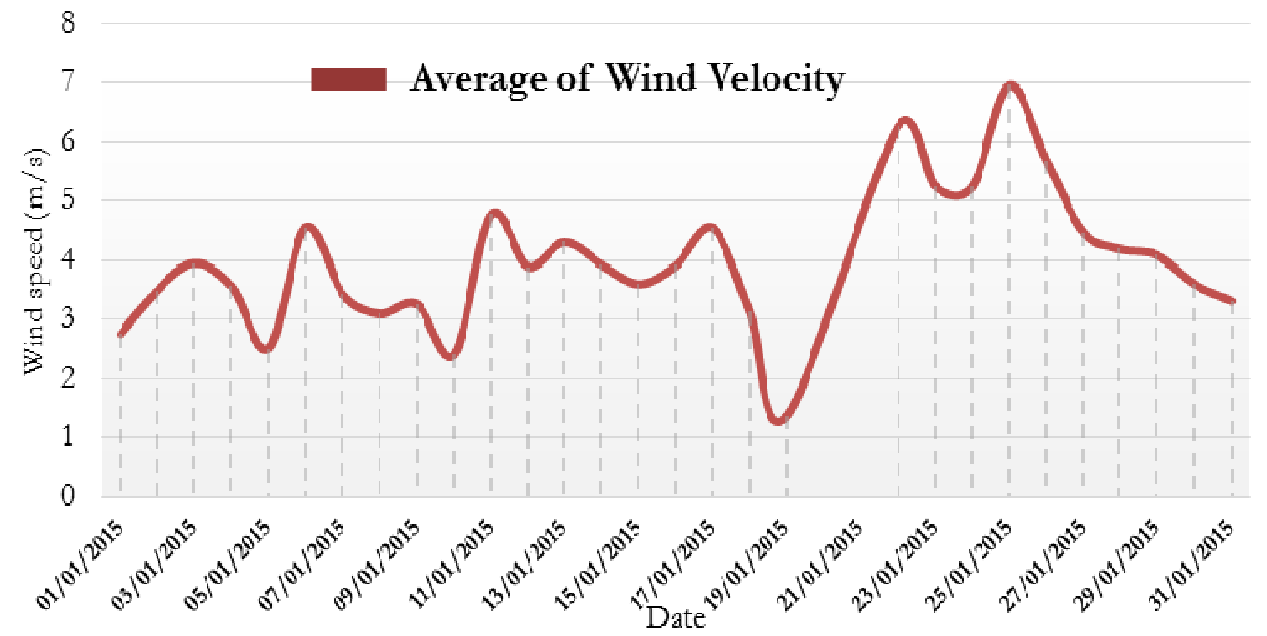

Fig. 6 Daily average wind velocity recorded by the weather station on January 2015.

in the summer as shown in Fig. 5, some difference was observed between the current simulation and NASA data. The later uses data collected from geostationary satellites as a primary input into their models. The visible channel from geostationary satellites provides information on the reflection earth-atmosphere system. This method is used for estimating data over large geographic areas but impractical for local assessments. This explains the gap observed between the curves.

The data collected at the University of Djibouti is used to calibrate and validate national strategies for natural ventilation in buildings. Consequently, the use of natural ventilation is definitely an advantage in winter with an average temperature of
$25{ }^{\circ} \mathrm{C}$. In summer, as shown in Fig. 5 the outside temperature is very high and natural ventilation is to be avoided.

This reliability is further complimented by another important analysis; that is, the wind velocity. Fig. 6showsthat the average of wind velocity in the cool season's month of January varies from $1 \mathrm{~m} / \mathrm{s}$ to $7 \mathrm{~m} / \mathrm{s}$ at the University of Djibouti as given by the weather station.

From the analysis above, air conditioned offices and living spaces are essential at least in hot climate like Djibouti one. Yet only a part of the population can afford air conditioning which is extremely expensive for two main reasons:

- The high price of electricity 
- Particularly bad thermal characteristics of the buildings.

However in cool season, it should be possible to dispense with cooling by improving natural ventilation and thermal quality of buildings.

\section{Air flow Simulation}

\subsection{Principles and Elements of Natural Ventilation}

Wind is a natural phenomenon that involves the flow of a fluid $\left(\rho=1.225 \mathrm{~kg} / \mathrm{m}^{3}\right)$ at a certain velocity. Since the studied structures are found in atmospheric boundary layer, the air flow is turbulent. In atmospheric boundary layer, the average wind speed profile is not constant. Several models [24, 25] take into account the variation of the average speed based on altitude. The most common are the logarithmic profile which is given by following equation Eq. 1 .

$$
U(z)=k_{r} \times U_{r e f} \ln \left(\frac{z}{z_{0}}\right)
$$

Where $\mathrm{U}(\mathrm{z})$ is the wind speed at a height $\mathrm{z}$ above the ground, $k_{r}$ is the Von Karman constant, $U_{\text {ref }}$ is the wind speed at the reference height and $z_{0}$, the aerodynamic roughness length.

The airflow simulation, in this work, is then based on the inlet conditions of the computational domain including modelling of flows in the urban boundary layer. Indeed, the computational domain is part of the urban boundary layer and must reproduce at best the soil roughness. Therefore, it was necessary to use local data of the site.

Due to the density and spaces between the university's buildings, the wind on the site was considered a class 3 of Eurocode $\left(\mathrm{z}_{0}=0.5 \mathrm{~m}\right.$ and $\mathrm{k}_{\mathrm{r}}=0.22$ ), regardless of its direction according to the standards NF 1991 action of the wind and National.

The inlet conditions are defined through a user-defined function that ensures the flow dynamics (velocity profile) and considers the turbulent characteristics of the boundary layer with a RANS-k-epsilon (Reynolds-average Navier-Stokes) model [25].
Natural ventilation is the movement of air through specific openings resulting from the natural forces produced by temperature differences and wind. Where thermal or buoyancy forces are present during the cooler season, the wind is the main ventilation force. Wind speed and direction, design and location of outlet and inlet openings determine the rate of ventilation volume. Natural ventilation differs from mechanical ventilation (air conditioner); the latter requires a mechanical energy input to produce the pressure differential necessary to produce air flow. This study will mainly deal with the wind effect because it is concerned with the optimization of building orientation for better winter ventilation [26].

The flow of air around a building caused by wind creates pressure gradients between surfaces i.e. transfer of dynamic pressure into static pressure head. Essentially, the wind velocity determinates the magnitude of the pressure exerted on the exterior of a building.

It is necessary to confirm that the incoming air could sufficiently ventilate the building. As a result, CFD simulations provide data on the airflow features of the envelope, leading to better understanding of the ventilation conditions in its interior.

\subsection{CFD Description}

To better meet the objectives of the study, one of the buildings of the University of Djibouti was selected as shown in Fig. 3. This pioneering work provides an overview of the natural ventilation potential using CFD in order to make a major contribution to the development of energy efficiency in Djibouti.

CFD is a known computational method to study single and multiphase in laminar or turbulent flow. ANSYS Fluent 14.5 software was used in the present simulations. The differential expressions of the Navier-Stokes equations for momentum, energy and mass balances were solved by the control volume approach [27]. 
Natural ventilation is more effective when the difference in altitude between air inlet and air outlet is greater. Consequently, a change had been made to the original geometry of the investigated building. To benefit from the pitch generated by air outlet, extraction openings are located in the vertical portion of roof. Conversely, the supply of fresh air openings is located in the lowest part of the walls [28, 29].

\subsection{Results and Discussions}

The wind conditions in the area of the building were carefully analysed and consecutive simulations with CFD software made possible to understand the precise effects of natural ventilation.

The CFD analysis used a wind speed of $0.5 \mathrm{~m} / \mathrm{s}$ from the East because most of the winter winds come from the East. The internal temperature is at $30{ }^{\circ} \mathrm{C}$. Initially the whole volume of air is at $30{ }^{\circ} \mathrm{C}$. The external fresh air is taken to $25^{\circ} \mathrm{C}$.
Diagrams of external and internal airflow simulation studies with CFD software are presented in Fig. 7.

As a high potential in renewable energy, Djibouti has a significant potential in natural ventilation. In winter, the use of natural ventilation is definitely an advantage with the rising concerns regarding the cost and the environmental impact of energy use. As shown in Fig. 7a, the airflow simulations revealed pressure differentials between the walls of the building. When wind blows across a building, fresh air will rush in the east wall facing the prevailing wind and exit the leeward wall opening to balance and relieve the pressures on the windward and leeward walls. It is thus possible to obtain ventilation through openings in the outside wall under the wind conditions studied.

The diagram of temperature in Fig. 7 (c-f) shows that at $\mathrm{t}=0 \mathrm{~min}$, the whole volume of air is at $30^{\circ} \mathrm{C}$.

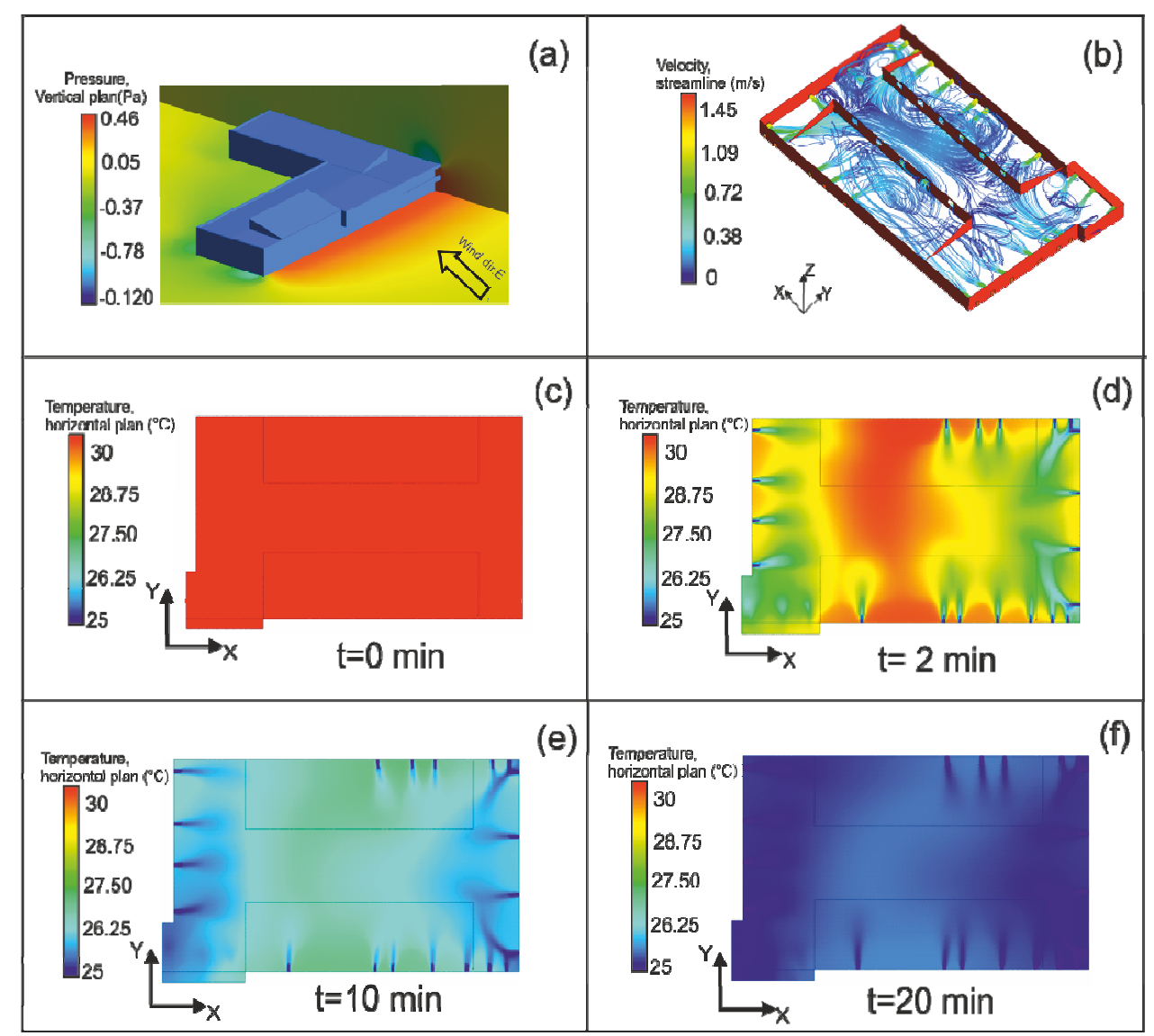

Fig. 7 External and internal airflow simulation: (a) Pressure Contours on a vertical plan; (b) Velocity streamline of the fresh air; (c-e) Temperatures on a horizontal plan. 
At $t=2 \mathrm{~min}$, the fresh air is diffused. It refreshes the initially present air. It is observed indeed that the red area of $30^{\circ} \mathrm{C}$ greatly reduces. At $t=10 \mathrm{~min}$, the fresh air has brought down the temperature on the entire surface. The contours are blue to light green; so the refreshing air is important. And finally at $t=20 \mathrm{~min}$, the contours are blue $\left(25^{\circ} \mathrm{C}\right)$. The entire surface is refreshed. This simulation shows that the fresh air fills the building quickly when the natural ventilation is active. The temperature of the inside air will be equal to the outdoor temperature.

There circulation of air inside the volume in Fig. 7b shows that the fresh air circulates throughout the volume. No dead spaces are identified. In addition, the air velocity peaks near the fresh air supply with 5.26 $\mathrm{km} / \mathrm{h}$ and the mean velocity is at $0.68 \mathrm{~km} / \mathrm{h}$. Heat exchange by convection is promoted by a recirculation of the air in the entire volume. This point refreshes the thermal mass as a whole, which contributes to the effectiveness of natural ventilation.

These results help and guide a country like Djibouti to optimize technical and architectural solutions maximising natural ventilation potential.

\section{Conclusions}

Natural ventilation is an alternative and sustainable approach to make use of passive cooling in buildings. This paper presented, on the basis of the local climate at the University of Djibouti, a numerical analysis using CFD to achieve ideal internal conditions for building in cool season. The techniques of CFD are expected to improve and contribute in design and analysis of more complex natural ventilation scenarios. There were some limitations to the study. The study remains theoretical and the results are location dependent. The implications of these data regarding energy are potentially intriguing. To make best of this explorative study, the concept of natural ventilation in hot climate must be extended and coupled with the economic and energy consumption parameters. In the current local regulatory environment and energy economics of the republic of Djibouti, it is too far to think about the application of natural ventilation.

Human being spends $80 \%$ to $90 \%$ of their time in their homes or in enclosed spaces. The Bioclimatic design is essential for several reasons:

- Provide thermal comfort and create a feeling of freshness inside buildings.

- Provide the comfort and hygiene of buildings. Poor air quality and thus poor ventilation may cause damages such as headaches, fatigue, and breathing difficulty for occupants.

- Eliminate excess humidity, bring fresh air, and thus supply oxygen needs.

- Reduce the energy consumption of buildings to low levels.

To develop natural ventilation in Djibouti, this study is a first step of the bioclimatic design using CFD software. This study will be in Djibouti, an example of environmentally responsible architecture that points to certain visionary technological possibilities. The results of this study can be considered applicable to most of the countries and regions, which have similar climatic conditions.

\section{Acknowledgments}

This work has been made possible thanks to the cooperation agreement between the University of Djibouti and the CERD (the Institute for Earth Sciences, Centre d'Etudes et de Recherche de Djibouti), the national research centre.Authors would like to thank the University of Djibouti for funding this research project. We are also grateful to Mr Omar Abdoulkader Mohamed for helping us to provide survey data in wind and we will like to thank $\mathrm{Mr}$ Osman Elmi for fruitful discussions.

\section{Reference}

[1] Melaragno, M. 1982. Wind in Architectural and Environmental Design. Van Nostrand Reinhold, New York.

[2] Richard, H. 2001. Climate Responsible Design: A Study of Buildings in Moderate and Hot Humid Climates. St 
Edmundsbury Press.

[3] Wang, L., Wong Nyuk, H., and Li, S. 2007. "Facade design optimization for naturally ventilated residential buildings in Singapore." Energy and Buildings 39: 954-61.

[4] Attia, S., and De Herde, A. 2009, "Bioclimatic Architecture: Design Strategies in Egypt." Sustainable Energy Technologies, Aachen, Germany, 2009.

[5] Givoni, B. 1992. "Comfort, climate analysis and building design guidelines." Energy and Buildings 18: 11-23.

[6] Hatamipour, M. S., and Abedi, A. 2008 "Passive cooling systems in buildings: Some useful experiences from ancient architecture for natural cooling in a hot and humid region." Energy Conversion and Management, 49: 2317-23.

[7] Yao, R., Li, B., Steemers, K., and Short, A. 2009. "Assessing the natural ventilation cooling potential of office buildings in different climate zones in China." Renewable Energy 34: 2697-705.

[8] Wong, N. H., and Heryanto, S. 2004. "The study of active stack effect to enhance natural ventilation using wind tunnel and computational fluid dynamics (CFD) simulations." Energy and Buildings 36: 668-78.

[9] Allocca, C., Chen, Q., and Glicksman, L. R. 2003. "Design analysis of single-sided natural ventilation." Energy and Buildings 35: 785-95.

[10] Al-Hinai, H., Batty, J., and Probert, S. D. 1993. "Vernacu-lar architecture of Oman: Features that enhance thermal comfort achieved within buildings." Applied Energy 44: 233-44.

[11] ASHRAE Standard. 2010. Thermal environmental conditions for human occupancy. Atlanta, GA: American Society of Heating, Refrigeration, Air-Conditioning Engineers.

[12] Bruce, J. M. 1978. "Natural convection through openings and its application to cattle building ventilation." Journal of Agricultural Engineering Research 23: 151-67.

[13] Axley, J., and Emmerich, S. 2002. "A method to assess the suitability of a climate for natural ventilation of commercial buildings." Presented at 9th International Conference on Indoor Air Quality and Climate in Monterey, California.

[14] Ahmed Aye, F. 2009. "Integration of Renewable Energy for Sustainable Energy Policy: Djibouti.” Ph.D. thesis, University of Corsica, France.

[15] Assowe, O. 2015. "The potential wind energy resource in Djibouti." Presented at East Africa Environmental risks and opportunities summit. The Republic of Djibouti.

[16] Idris, A. 2014. Calculs CFD appliqués à la thermique des bâtiments et conception énergétique.

[17] Idris, A. O., and Idriss, A. I. 2015. "Green Buildings and Energy Efficient retrofits save money on energy, while reducing environmental Impacts in Djibouti." Presented at East Africa Environmental risks and opportunities summit, The Republic of Djibouti.

[18] IRENA (International Renewable Energy Agency), 2012. Renewables readiness assesment Djibouti.

[19] ADME, 2015. Elaboration d'une stratégie et d'un plan d'action de maîtrise de l'énergie à Ministère de l'Energie en charge des Ressources Naturelles, Djibouti.

[20] Jiang Y., and Chen, Q. 2002. "Effect of fluctuating wind direction on cross natural ventilation in buildings from large eddy simulation." Building and Environment 37: 379-86.

[21] Zhang, L., Gao, C., and Zhang, A. 2005. "Numerical Simulation of the Wind Field around Different Buildings Arrangements." Journal of Wind Engineering and Industrial Aerodynamics 12: 93.

[22] Dunham, D. 1983. "Construire dans la région du désert maritime." Volunteers in Technical Assistance (VITA). NASA, Surface meteorology and solar energy release 6.0, 2013. Accessed date: January 2015. http://https://eosweb.larc.nasa.gov/sse/.

[23] Versteeg, H. D., and Malalasekera, W. 1995. An Introduction to Computational Fluid Dynamics: The Finite Volume Method Approach, Wiley, New York.

[24] Tominaga, Y., and Stathopoulos, T. 2010. "Numerical simulation of dispersion around an isolated cubic building: Model evaluation of RANS and LES." Building and Environment 45: 2231-9.

[25] BS 5925, 1980. Code of Practice for Design of Buildings: Ventilation Principles and Designing for Natural Ventilation, British Standards Institution, London.

[26] Anderson, J. D. 1995. Computational Fluid Dynamics: The Basics with Applications, McGraw-Hill Inc., USA

[27] Werner, H., and Wengle, H. 1991. "Large eddy simulation of turbulent flow over and around a cube in a plate channel. Eighth Symposium on Turbulent Shear Flows." Ph.D. thesis, Technical University Munich, pp. 155-68.

[28] Haghighat, F., Rao, J., and Fazio, P. 1991. "The influence of turbulent wind on air change rates-a modeling approach." Building and Environment 26: 95-109. 